\title{
SOBRE A OCORRENCIA DE UMA NOVA PRAGA, HAEMATOBIA IRRITANS (L.) (DIPTERA, MUSCIDAE), NO BRASIL
}

JOSÉ RAUL VALÉRIO ${ }^{1}$ JOSÉ HENRIQUE GUIMARÃES 2

\begin{abstract}
The horn fly, Haematobia irritans (L.) (Diptera, Muscidae), is reported as introduced into Boa Vista, Roraima, Brasil, possibly from Northern South America (Venezuela).

Desde 1980 os técnicos do Centro Nacional de Pesquisas do Gado de Corte - Embrapa, têm conhecimento da existência de uma pequena mosca hematófaga que vem atacando o gado bovino em propriedades rurais e abatedouros no município de Boa Vista, Roraima. As moscas formam bandos, sugando os animais em várias áreas do corpo não atingidas pela cauda ou a cabeça dos animais. O gado atacado torna-se irritadiço, procurando refúgio em áreas de bosques.
\end{abstract}

As primeiras coletas destes dípteros na região foram feitas em vii. 1980 pelo Engenheiro Agrônomo Antônio Nascimento Rosa. Novas coletas foram realizadas em x.1981 pelo Médico Veterinário José Antônio Paim Schenk e enviadas para estudo a um dos autores (J.R.V.); acreditando tratar-se da Haematobia irritans (L.), tal amostra foi encaminhada ao Dr. Adrian C. Pont, British Museum (Nat. Hist.) para confirmação. O Dr. Pont prontamente identificou a amostra como Haematobia irritans (L.), confirmando as suspeitas anteriores.

Tal díptero, conhecido na literatura entomológica como "horn-fly", é uma séria praga do gado, bem conhecida nos países do Novo Mundo, da Venezuela ao Canadá.

Haematobia irritans assemelha-se externamente à mosca dos estábulos, Stomoxys calcitrans, diferenciando-se desta principalmente por apresentar o palpo espatulado, quase tão longo quanto a probóscida. A biologia e hábitos desta espécie foram revistos por McLintock \& Depner (1954). Os adultos são hematófagos, causando grandes prejuízos à pecuária. Os animais, perturbados pelo ataque da mosca, alimentam-se mal, com redução no ganho de peso ou na produção de leite. A perda de sangue pode ser considerável quando as moscas são abundantes.

Esta praga, originária do Velho Mundo, foi introduzida nos Estados Unidos entre 1884 e 1886 em gado importado da Europa; em 1898, já tinha se espalhado por todo o continente norte-americano (Marlatt, 1910).

A Hematobia sempre viaja com o seu hospedeiro. Myers (1938) acreditava que tal díptero fora introduzido nas Antilhas a partir de gado importado dos Estados Unidos. Na América do Sul, esta praga é conhecida em quase todos os países. Segundo Fiasson (1934) a Haematobia foi introduzida na Venezuela em 1937, de gado originário da Colômbia. Gonzalez (1968), registrou a introdução desta espécie em i.1967 no Chile. Até o presente não se tinha conhecimento da existência deste díptero no Brasil. Pont (1972), em seu catálogo da família Muscidae para a Região Neotropical, assinala a ocorrência desta espécie em nosso país. Entretanto, tal informação vem de registros não confirmados existentes na literatura, como o de Laake (1949) que relata a presença desta espécie em Minas Gerais. Não temos ainda conhecimento do país de

1. Centro Nacional de Pesquisas de Gado de Corte, Embrapa, Campo Grande, MS.

2. Museu de Zoologia, Universidade de São Paulo. Pesquisador do Conselho Nacional de Desenvolvimento Científico e Tecnológico, CNPq. 
onde tal mosca possa ter vindo e nem de sua atual dispersão na região amazônica. O país de origem mais provável seria a Venezuela, que faz fronteira com Roraima e onde tal praga ocorre.

Os exemplares identificados pelo Dr. Pont foram depositados na coleção do Museu de Zoologia, Universidade de São Paulo.

\section{REFERENCIAS}

Fiasson, R., 1943. Notes sur les parasites animaux du Haut-Apure (Venezuela). Revue Sci. méd. pharm. vét. Afr. fr. libre 2(2): 125-151, 5 pls., mapa. Gonzalez, R. H., 1968. Haemotobia irritans (L.) in Chile. Revta chil. Ent. 6: 142.

Laake, E. W., 1949. Livestock parasite control investigations and demonstrations in Brazil. J. econ. Ent. 42(2): 276-280.

Marlatt, C. L., 1900. The horn fly (Haematobia serrata, Rob.-Desv.). U. S. Dep. Agric. Bur. Ent. Circ. 115.

McLintock, J. \& K. R. Depner, 1954. A review of the life-history and habits of Siphona irritans (L.) (Diptera, Muscidae). Can. Ent. 86: 20-33.

Myers, J. G., 1938. Report on the natural enemies of the horn-fly (Lyperosia irritans) and the green tomato bug (Nezara viridula). J. Counc. Sci. ind. Res. 11: 35-46.

Pont, A. C., 1972. Family Muscidae, in Museu de Zoologia, Universidade de São Paulo, A Catalogue of the Diptera of the Americas South of the United States 97: 1-111. São Paulo. 